Original article

\title{
Survey on serum acetylecholinesterase (SAChE) activity in selected farming communities at risk of organophosphate exposure, Southern Ghana
}

\author{
Ato Kwamena Tetteh ${ }^{1}$, Gertrude Adu-Afari ${ }^{1}$, Emmanuel Nana Yaw Effrim Botchway ${ }^{2}$, Gifty Rhodalyn Tetteh ${ }^{3}$, \\ Edward Agyarko ${ }^{4}$
}

\author{
${ }^{1}$ Metropolitan Hospital, Cape Coast, Central Region, Ghana \\ ${ }^{2}$ Cape Coast Teaching Hospital, Cape Coast, Central Region, Ghana \\ ${ }^{3}$ University of Cape Coast, Cape Coast, Central Region, Ghana \\ ${ }^{4}$ Anglican University College of Technology, Nkoranza, Brong Ahafo Region, Ghana
}

Received 13 March 2017, Revised 13 June 2017, Accepted 6 July 2017

(C) 2017, Tetteh A.K., Adu-Afari G., Botchway E.N.Y.E., Tetteh G.R., Agyarko E.

(C) 2017, Russian Open Medical Journal

\begin{abstract}
Aim - This study aimed at providing baseline information for the first time in Ghana, on the extent of organophosphorus (OP) pesticide exposure and risk of poisoning by a qualitative estimation of serum acetylcholinesterase activity.

Material and Methods - The study was cross-sectional, involving 963 participants who consented to being screened for serum acetylcholinesterase (SAChE) activity, using the dry chemistry test strips. The SAChE activity was then categorized into normal, low or high risk of developing symptoms associated with OP poisoning.

Results - The total group included $54.5 \%$ females and $45.5 \%$ males. Majority were crop farmers (46.3\%) and students/pupils (30.8\%). The remaining $22.9 \%$ consisted mainly of traders, teachers, fishermen/fish processors, drivers and dressmakers. Very low SAChE activity unit of $<30 \mathrm{U} / \mathrm{ml}$ (high risk of OP poisoning) was detected in $50.7 \%$, while $41.8 \%$ had fairly low activity unit $=30 \mathrm{U} / \mathrm{ml}$ (low risk of OP poisoning). Only 7.5\% had normal activity unit of $>30 \mathrm{U} / \mathrm{ml}$. By this, a significant majority had either low or high risk of developing OP poisoning $\left(\chi^{2}=4.43,95 \% \mathrm{Cl}: 4.12-4.65, \mathrm{p}=0.014\right)$ compared with those with normal activity. Most of the participants were in the 10-19 years age group of which $15.6 \%$ were in the high risk category, while $13.6 \%$ had low risk of OP poisoning. Reduced SAChE activity was predominant among all age groups compared with those with normal activity of the enzyme. As well, $27.3 \%$ who were females had reduced SAChE activity rate $<30 \mathrm{U} / \mathrm{ml}$ (high risk of OP poisoning). Similarly, $23.4 \%$ of males were also at high risk of OP poisoning. There was however no statistical significance between the sex with regards to the numbers at risk of OP poisoning $\left.\chi^{2}=4.80,95 \% \mathrm{Cl}: 4.25-4.75, p=0.160\right)$.

Conclusion - This study provides some evidence of exposure, deduced from reduced SAChE activity, which potentially puts participants at a high risk of developing symptoms associated with OP poisoning. A follow-up study might be able to suggest to physicians in Ghana considering diagnostics of OP poisoning, especially for clients from farming communities where pesticides are used extensively.
\end{abstract}

Keywords: serum acetylcholinesterase, enzyme activity, organophosphates, pesticides, exposure, crop farmers

Cite as Tetteh AK, Adu-Afari G, Botchway ENYE, Tetteh GR, Agyarko E. Survey on serum acetylecholinesterase (SAChE) activity in selected farming communities at risk of organophosphate exposure, Southern Ghana. Russian Open Medical Journal $2017 ; 6$ : e0401.

Correspondence to Ato Kwamena Tetteh. Address: Laboratory Department, Metropolitan Hospital, P. O. Box 174, Cape Coast, Central Region, Ghana. E-mail: aktetteh@outlook.com

\section{Introduction}

Over the past decade, Ghana has seen an increased use of pesticides in farms and in most homes which are burdened by pests, including vectors of various tropical diseases [1, 2]. It is estimated that between 1995 and 2000 alone, about 21 types of pesticides were imported into the country [2]. Available pesticides, mostly organophosphates (OP) and carbamates, kill, deter or attack pests that have harmful outcomes. These are classified as herbicides, insecticides, fungicides, rodenticides, molluscicides, plant growth regulators, desiccants and defoliants, and acaricides depending on the targeted pest [3]. In Ghana and elsewhere, OPs are regularly used as a form of pest control on most farms, and crop farmers have improved their appreciation of pesticide use and handling. However, many are still not meeting the full range of personal protection standards in their handling and application [46]. This exposes crop farmers, their households, consumers and domesticated animals to such fatally harmful chemicals. Routes of human and animal exposure include dermal absorption, inhalation and ingestion [7]. It is also known that practices such as mixing pesticide-contaminated laundry, storing pesticides in the home [8], and storing food and drinking water in used/empty pesticide containers (personal communication with a Ministry of Agriculture Extension Officer) are not only common causes of exposure to the farmer and farm worker, but may also be placing other household members, particularly children at risk. 


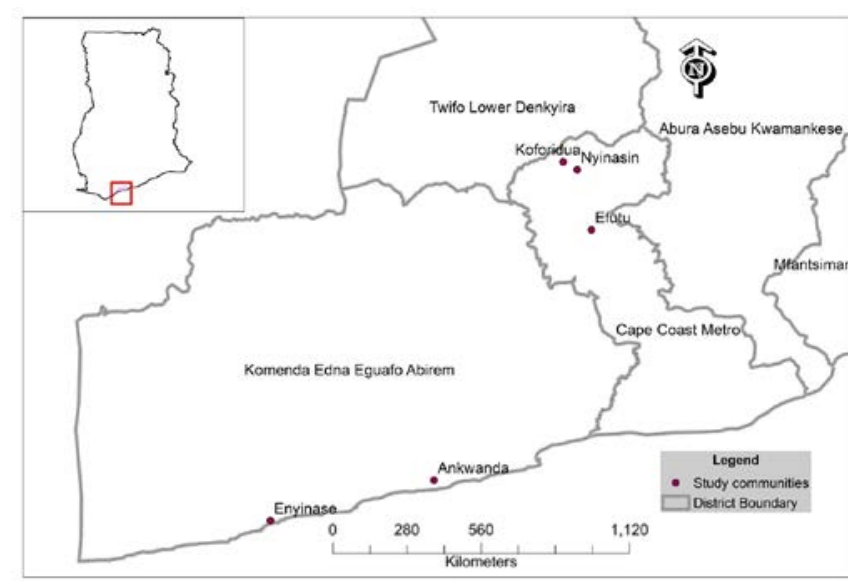

Figure 1. Map showing study sites (Credit: Charles Gyamfi, PhD, Department of Civil Engineering, Tshwane University of Technology, Pretoria, South Africa).

The OP class of pesticides affects the nervous system with poisoning most common among crop farmers and children $[9,10]$. Acetylcholinesterase (AChE), also known as cholinesterase is a protein in the body whose biological role is the termination of impulse transmission at the cholinergic synapses by rapid hydrolysis of the neurotransmitter acetylcholine (ACh) to yield choline [11]. Symptoms of OP toxicity are caused by inactivation of AChE, where the serine hydroxyl group located at the active site is phosphorylated [12]. This will result in the subsequent accumulation of acetylcholine at the cholinergic synapses of nerves, causing an over stimulation of muscarinic and nicotinic receptors, and eventually, an uncontrolled firing of the synapse [12-14]. There is therefore an overstimulation and subsequent blockage of nerve stimuli (cholinergic crisis). Subclinical effects of chronic OP exposure such as AChE inhibition may be detected early by biological tests. Recovery from AChE depression is prolonged, due to the permanent binding of OPs to the red blood cell and its consequent 120 day life cycle [15]. When cholinesterase levels are low because of excessive inhibition, the nervous system can malfunction, producing pesticide-poisoning symptoms such as fatigue, lightheadedness, nausea, vomiting, headaches, and seizures. If levels get low enough, subsequent exposure to OP or carbamate insecticides can result in death.

Monitoring exposure to organophosphates involves the measurement of serum cholinesterase (SAChE) and/or erythrocyte cholinesterase (EAChE) which are peripheral cholinesterase enzymes that are inhibited by organophosphates. Since the effect of these pesticides is cumulative, it is obligatory that all exposed individuals are monitored. This study aimed at an estimation of SAChE activity, and highlights pesticide exposure as a risk of developing $\mathrm{OP}$ poisoning for crop farmers, their families and consumers of farm produce. It is as well expected to form the basis for trumpeting the use of personal protective equipment (PPEs) in farming communities. The study will also provide baseline information to health care providers and suggest the integration of cholinesterase testing procedures into point of care (POC) health checks.

\section{Material and Methods}

\section{Study population and design}

The study was cross-sectional involving a total of 963 participants from five main farming communities, namely, Enyinase, Ankwanda,
Efutu, Nyinasin and Koforidua (Figure 1). Some individuals from Asenadze and other surrounding villages of these main communities who had previously been briefed also participated.

\section{Consent}

Consent was sought from chiefs/community leaders and briefed on the essence of the test as well as the procedure involved. Prior to being tested, participants were briefed extensively at a public forum in the presence of Agricultural Extension Officers on the sample required for the test. As many as consented were made to fill a consent form. Minors were also asked to fill assent forms, after which copies were given to them. Before venous blood sample collection, information such as participant's name, age, sex, occupation, telephone numbers and the town where they reside was documented. They were assured that the information will be used for scientific and educational purposes as explained, and that identities of participants will be secluded.

\section{Blood collection}

The closed system of blood draw was used in the blood collection. This was done by three experienced Biomedical Laboratory Scientists from the Metropolitan Hospital and the Cape Coast Teaching Hospital (CCTH), both in Cape Coast. The Becton, Dickinson (BD) Eclipse ${ }^{\mathrm{TM}}$ Safety Needles, Holders, and $5 \mathrm{ml}$ BD Vacutainer $^{\circledR}$ Rapid Serum Tubes (RST) were used to collect approximately $2.5 \mathrm{ml}$ of blood, as has been expansively outlined by the manufacturer. The entire sample collection took a period of one month. After collection each day, samples were transported to the Metropolitan Hospital Laboratory, by which time serum had already separated from blood corpuscles, paving way for testing.

\section{SAChE testing}

The Dry Chemistry Acetylcholinesterase Activity Assay kit (Nantong Egens Biotechnology Co. Ltd) was used. This involved a test strip which produced a range of colours specified by the manufacturer on a scale (modified from Ellman et al., 1961 [16]). The colours produced indicate a specific activity unit, which was a measure of the extent of exposure and therefore risk of OP poisoning.

\section{Principle of test}

Acetylcholine (ACh) is hydrolyzed by cholinesterase to produce acetic acid and choline. The acetic acid produced reduces the $\mathrm{pH}$ of the serum, which changes the test strip from blue to yellow:

$\mathrm{CH}_{3} \mathrm{C}(\mathrm{O}) \mathrm{OCH}_{2} \mathrm{CH}_{2} \stackrel{+}{\mathrm{N}}\left(\mathrm{CH}_{3}\right)_{3}+\mathrm{H}_{2} \mathrm{O} \stackrel{\mathrm{AChE}}{\longrightarrow} \mathrm{CH}_{3} \mathrm{COOH}+\mathrm{HOCH}_{2} \mathrm{CH}_{2} \stackrel{+}{\mathrm{N}}\left(\mathrm{CH}_{3}\right)_{3}$

\begin{tabular}{|l|l|l|l|l|l|}
\hline \multicolumn{7}{|c|}{$\mathrm{U} / \mathrm{ml}$} \\
\hline 75 & 60 & 45 & 30 & 15 & 0 \\
\hline
\end{tabular}

This indicates that there is cholinesterase activity. If the test kit remains blue, it indicates no activity. There are also different shades of blue, bluish-green or yellowish-green, which depicts different levels of activity. In this study $30 \mathrm{U} / \mathrm{ml}$ was seen as intermediate (low risk of OP poisoning) as per manufacturer's classification. Values with colours below $30 \mathrm{U} / \mathrm{ml}$ are classified as low/no cholinesterase activity (high risk of OP poisoning). Likewise, values above $30 \mathrm{U} / \mathrm{ml}$ indicate high cholinesterase activity (normal - no risk of OP poisoning). 
Table 1. Demographics of participants

\begin{tabular}{|c|c|c|c|c|c|c|c|c|c|}
\hline \multirow[t]{2}{*}{ Sex } & \multicolumn{8}{|c|}{ Age range of participants, years } & \multirow[t]{2}{*}{ Total } \\
\hline & $10-19$ & $20-29$ & $30-39$ & $40-49$ & $50-59$ & $60-69$ & $70-79$ & $80-89$ & \\
\hline Female & 163 & 79 & 74 & 74 & 60 & 41 & 25 & 9 & 525 \\
\hline Male & 132 & 72. & 55 & 55 & 49 & 29 & 21. & 5 & 438 \\
\hline Total & 295 & 151 & 129 & 129 & 109 & 70 & 46 & 14 & 963 \\
\hline
\end{tabular}

Table 2. Occupation of participants in the study

\begin{tabular}{|c|c|c|}
\hline Occupation of participants & No. involved & Percentage, \% \\
\hline Crop farmers & 446 & 46.3 \\
\hline Students/Pupils & 297 & 30.8 \\
\hline Traders & 71 & 7.4 \\
\hline Teachers & 25 & 2.6 \\
\hline Drivers & 22 & 2.3 \\
\hline Seamstresses & 18 & 1.9 \\
\hline FishProcessors & 12 & 1.2 \\
\hline Fishermen & 11. & 1.1 \\
\hline Carpenters & 9 & 0.9 \\
\hline Hairdressers & 7 & 0.7 \\
\hline Cooks & 5 & 0.5 \\
\hline Masons & 5 & 0.5 \\
\hline Food vendors & 4 & 0.4 \\
\hline Agric extension officers & 3 & 0.3 \\
\hline Security personnel & 3 & 0.3 \\
\hline Tailors & 3 & 0.3 \\
\hline Laborers & 2 & 0.2 \\
\hline Welders & 2. & 0.2 \\
\hline Cassava processors & 1 & 0.1 \\
\hline Civilservants & 1 & 0.1 \\
\hline Electricians & 1 & 0.1 \\
\hline HeadPorters & 1 & 0.1 \\
\hline OilProcessors & 1 & 0.1 \\
\hline Poultry farmers & 1 & 0.1 \\
\hline School administrators & 1 & 0.1 \\
\hline Shoe repairers & 1 & 0.1 \\
\hline Waiters & 1 & 0.1 \\
\hline
\end{tabular}

Table 3. Risk categorization among participants after testing

\begin{tabular}{lc}
\hline Risk categories* & No. involved (\%) \\
\hline Normal-activity unit $>30 \mathrm{U} / \mathrm{ml}$ & $72(7.5)$ \\
Low risk-activity unit $=30 \mathrm{U} / \mathrm{ml}$ & $403(41.8)^{* *}$ \\
High risk-activity unit $<30 \mathrm{U} / \mathrm{ml}$ & $488(50.7)^{* *}$ \\
\hline Total & 963
\end{tabular}

Total

*Normal activity - No risk of OP poisoning; Low risk - Low risk of OP poisoning; High risk - high risk of OP poisoning.

**Level of risk significant compared with participants with Normal activity/no risk $\left(\chi^{2}=4.43,95 \% \mathrm{Cl}: 4.12-4.65, \mathrm{p}=0.014\right)$.

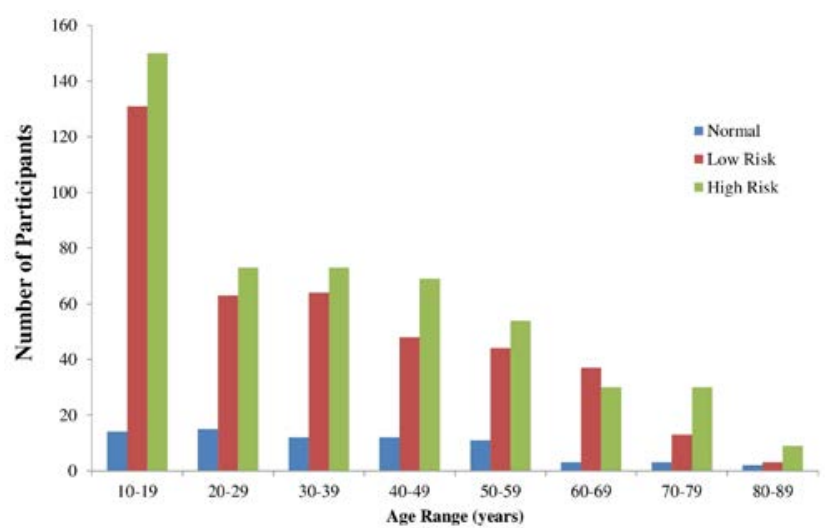

Figure 2. Cholinesterase activity among age groups.

A significant majority were at risk of OP poisoning $\left(\chi^{2}=4.43,95 \% \mathrm{Cl}: 4.12-\right.$ 4.65, $p=0.014)$.

\section{Testing procedure}

For each serum sample, one labeled cholinesterase test strip was dipped and allowed to soak for approximately 20 seconds. Following this the strip was allowed to incubate for 10-30 minutes at room temperature, as specified by the manufacturer's testing protocol. The resulting colour of the test strip was then compared to the standard colour chart to obtain the cholinesterase activity unit.

\section{Statistical analysis}

Field results previously compiled into a Microsoft Excel sheet was exported into the SPSS package ${ }^{\circledR}$ (Version 20) and used to estimate frequencies, percentages and categorized the activity units of cholinesterase into Normal $(>30)$, Low risk $(=30)$ and High risk $(<30)$. The Chi-square $\left(\chi^{2}\right)$ test was performed to determine the difference in significance at $p=0.05$.

\section{Results}

\section{Participants' information}

A total of 936 participants including crop farmers and individuals living or working in farming communities participated in the study (Table 1). They consisted of 525 females and 438 males, ranging from 10-89 years. Majority of the participants were between $10-59$ years old (Table 1 ).

\section{Occupation of participants}

Participants were drawn from diverse occupations as represented in Table 2. Of the total, 46.3\% (446/963) were crop farmers, while $30.8 \%$ (297/963) were students/pupils, and these constituted the majority. Students were from both Junior High and Senior High schools living in farming communities and were involved in farming activities. Apart from these two categories, traders $(7.4 \%$, $71 / 963)$, teachers $(2.6 \%, 25 / 963)$, fishermen/fish processors $(2.4 \%$, $23 / 963)$, drivers $(2.3 \%, 22 / 963)$, and seamstresses $(1.9 \%, 18 / 963)$ constituted appreciable participation. The remaining occupations were all below $1.0 \%$ represented the minority.

\section{Risk categorization of OP exposure}

Of the total number of participants, $92.5 \%(891 / 963)$ were at risk (Table 3). Out of this number, $41.8 \%$ (403/963) belonged to the low risk group, while $50.7 \%$ (488/963) were of high risk $\left(\chi^{2}=4.43,95 \% \mathrm{Cl}: 4.12-4.65, \mathrm{p}=0.014\right)$. The remaining $7.5 \%(72 / 963)$ had normal cholinesterase activity as indicated in Table 3.

\section{Risk categorization among age groups}

As already described, the cholinesterase activity value determined provides an estimation of the extent of OP poisoning. Participants were placed in 10 years age groups (Figure 2 ) and cross-tabulated with the extent of risk. Comparatively, majority of the participants were in the $10-19$ years age group, of which $15.6 \%$ (150/963) were at high risk, while $13.6 \%(131 / 963)$ were at low risk of OP poisoning. The risk of exposure (both low and high) was high in all the age groups compared 
with those who have normal cholinesterase activity (Figure 2).

\section{Risk categorization among males and females}

Although the difference was insignificant, more females than males participated in the survey as shown in Figure 3. Of the total, $27.3 \%$ (263/963) who were females were at high risk, while $23.1 \%$ (222/963) were low risk. More of the males $23.4 \%$ (225/963) were in the high risk group while $18.8 \%(181 / 963)$ were in the low risk group. The difference in risk among males and females was insignificant $\left(\chi^{2}=4.80,95 \% \mathrm{Cl}: 4.25-4.75, p=0.160\right)$.

\section{Discussion}

The eventual cumulative dire consequences of OPs on humans are known worldwide but have been inadequately studied in Ghana. As it stands, there are no laboratory diagnostic protocols, or presumptive diagnosis available for detecting and managing $O P$ intoxication in any of the numerous health facilities scattered across the Country. This study was therefore necessary as it provides preliminary information on the extent of exposure in some selected 'at risk' farming communities, to assist in future management of such intoxication.

Pesticide poisoning can be differentiated by intentional and unintentional exposure. Unintentional exposure can be broken into occupational and non-occupational categories and defined by long-term and short-term exposure. Most non-occupational poisonings occur through ingestion of contaminated food and water and, in cases suicide, by direct consumption [17]. The study did not discriminate among participants; all those willing to participate were included. However, crop farmers and students constituted the majority. Other occupations that were in the communities as at the time of the study and consented were included. Students and pupils were included because extension officers confirmed that they participated actively in applying pesticides.

The study was preceded by community education on the risk involved in pesticide application and ingestion of farm produce where pesticides were applied. Non-farming residents who were convinced of their being potentially exposed also consented. Pesticides when applied on matured fruits/vegetables must decompose in about 2 weeks before being harvested for the market. If consumed without proper washing could lead to direct ingestion of pesticides. Generally, the public is at risk since we cannot be sure if these crop farmers do the right thing on the farms prior to harvesting. It is worth mentioning that crop farmers at the study sites are mostly vegetable and watermelon growers. Vegetables are mostly eaten raw or partially cooked and therefore require thorough washing, or risk ingesting high doses of OPs. We recommend mass education of the general public on the dangers involved in exposure to pesticides.

The extent of exposure was determined by categorizing the SAChE activity levels into 'Normal' 'Low Risk' or 'High Risk'. After categorizing participants into the levels of risks, it became evident that more than $95 \%$ were at risk $(\leq 30 \mathrm{U} / \mathrm{ml})$. This means they had reduced cholinesterase activity. Especially of critical concern is the over $50 \%$ who were in the high risk category. Individuals within this category are considered to be at high risk of developing symptoms associated with organophosphate bioaccumulation in the near future. Three of the Authors from both Metropolitan Hospital and Cape Coast Teaching Hospital were tasked to cross check not less than 500 folders in their hospitals to find out if any Physician had previously diagnosed OP poisoning. The responses (data not shown) clearly indicated that such diagnosis is unpopular among the myriad of conditions documented. Enquiries made at the District Health Information Management System (DHIMS) in the two hospitals indicated that such information was unavailable. It is uncertain if OP poisoning has been misdiagnosed for any of the many tropical ailments with similar symptoms in the past. We are hopeful that subsequent field studies will include Physicians to enable us report on OP poisoning at our study sites.

This study presents data on women and children, who cannot be overlooked in Ghana. They constitute major farm hands in most commercial and subsistent agriculture in Ghana. Observations at the study sites clearly indicate that their role in pesticide application or their close proximity to the application site cannot be overlooked. Although their interaction with the environment may be different, each is exposed to hazards and illnesses $[18,19]$. This study revealed that $50.4 \%$ of women were exposed and therefore at risk of OP poisoning, compared to $42.2 \%$ of men. Elsewhere in Kenya, out of 455 reported poisoning cases, 31.4\% were women while $38.5 \%$ were men. Similarly in Tanzania, of 736 cases, $48.4 \%$ were women while $44.8 \%$ were men [20]. Results obtained in this study are consistent with that from these mentioned countries.

The 10-19 year old age group was the majority at risk. These were mostly students/pupils who were used as farmhands after school by their parents. Informal communication with field extension officers revealed that these children are assigned the role of applying pesticides on the farms. Adult crop farmers although have been trained on the use of PPEs, do not comply and therefore are unable to transfer knowledge acquired. Noncompliance to the use of PPEs by the 10-19 year age group could be blamed on parents who care less about the consequences on their children. The Agric Extension officers suggest legislation on the importation of pesticides, which must be accompanied by the corresponding PPEs. It should be possible to enforce strict measures to ensure that children $<18$ years are not allowed to apply pesticides.

\section{Conclusion}

The extent of exposure deduced from the SAChE activity prompts regulators to enforce the appropriate use of pesticides in Ghana. Follow-up studies will in addition document clinical manifestations to benefit management of poisoning due to exposure to OPs.

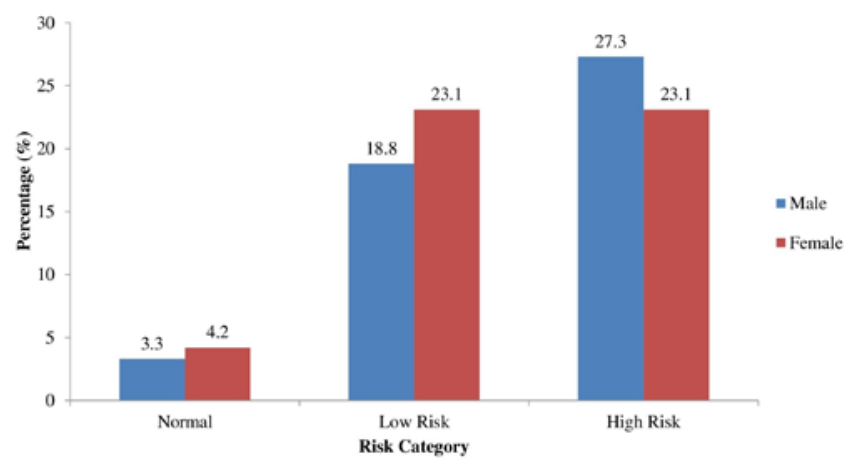

Figure 3. Risk categorization among sex 


\section{Limitations}

Our initial decision to conduct this study was mainly to detect only cholinesterase enzyme activity, and translate low activity as possible exposure to organophosphates. Ideally blood samples are to be collected within four hours of exposure. After four hours, reactivation of the enzyme is expected, except for individuals with consistent exposures. Blood sample collection was random and not specific to time of pesticide application. It is documented that enzyme activity may be reduced in female participants who consume oral contraceptives. Hepatic disease may also cause up to a $70 \%$ decrease in enzyme levels. Cholinesterase activity may be slightly elevated in participants with obesity or diabetes. A decision to include medical officers to provide us with clinical summaries (signs and symptoms of exposure/poisoning) of participants in this study came as a postscript. We therefore recommend that future studies incorporate medical officers to clerk participants for their clinical history and ascertain the impact of the extent of exposure detected.

\section{Conflict of interest}

The authors declare that there is no conflict of interest.

\section{Acknowledgements}

We express our sincere thanks to our collaborators, mainly, the Chiefs, Heads and Teachers of all schools and Agric Field Extension Officers at the study sites. Our special appreciation goes to Charles Gyamfi (PhD), Research Fellow, Department of Civil Engineering, Tshwane University of Technology, Pretoria, South Africa for locating our study sites and designing the map used for this study.

\section{References}

1. Ware GW. The pesticide book. 4th Ed. Fresno, CA: Thompson Publishers, 1994

2. Ministry of Food and Agriculture (MOFA). Agriculture in Ghana: facts and figures. Accra: Statistics, Research and Information Directorate, 2003.

3. Ntow JW, Gijzen H J, Kelderman P, Drechsel P. Farmer perception and pesticide use practices in vegetable production in Ghana. Pest Manag Sci 2006; 62(4): 356-365. https://doi.org/10.1002/ps.1178.

4. Yeboah FA, Mensah F O, Afreh AK. The probable toxic effects of aerosol pesticides on hepatic function among farmers at Akomadan/Afrancho Traditional Area of Ghana. J Ghana Sci Assoc 2004; 6(2): 39-43.

5. Mensah FO, Yeboah FA, Akman M. Survey of the effect of aerosol pesticide usage on the health of farmers in the Akomadan and Afrancho farming community. J Ghana Sci Assoc 2004; 6(2): 44-48.

6. Radcliffe J. Pesticide use in Australia. Parkville: Australian Acadamy of Technological Sciences and Engineering, 2002.

7. Jones A, Gray B, Schaefer M. ChemCert AgVet Chemical Users Course Resource Manual. Warragul: ChemCert Australia (Vic) Inc, 2011.

8. Strong LL, Starks HE, Meischke H, Thompson B. Perspectives of mothers in farmworker households on reducing the take-home pathway of pesticide exposure. Health Educ Behav 2009; 36(5): 915929. https://doi.org/10.1177/1090198108328911.

9. O'Malley M. Clinical evaluation of pesticide exposure and poisonings. Lancet 1997; 349(9059): 1161-1166. https://doi.org/10.1016/S01406736(96)07222-4.

10. Kwong TC. Organophoshate pesticides: biochemistry and clinical toxicology. Ther Drug Monit 2002; 21(1): 144-149. https://www.ncbi.nlm.nih.gov/pubmed/11805735.

11. Bernard EA, Enzymatic destruction of acetylcholine. In: The peripheral nervous system. J.I. Hubbard, ed. New York: Plenum, 1974: 201-224.
12. Rusyniak DE, Nanagas KA. Organophosphate poisoning. Semin Neurol 2004; 24(2): 197-204. https://doi.org/10.1055/s-2004-830907.

13. Fragar L, Franklin R. The health and safety of Australia's farming community. Moree: ACAHS \& RIRDC, 2000.

14. Banks CN, Lein PJ. A review of experimental evidence linking neurotoxic organophosphorus compounds and inflammation. Neurotoxicology 2012; 33(3): 575-584. https://doi.org/10.1016/j.neuro.2012.02.002

15. Quandt SA, Chen H, Grzywarcz JG, Vallejos QM, Galvan L, Arcury TA. Cholinesterase depression and its association with pesticide exposure across the agricultural season among Latino farm workers in North Carolina. Environ Health Perspect 2010; 118(5): 635-639. https://doi.org/10.1289/ehp.0901492.

16. Ellman GL, Courtney DK, Andres V, Fearstone RM. A new and rapid colorimetric determination of acetylcholinesterase activity. Biochem Pharmacol 1961; 7(1): 88-95. https://www.ncbi.nlm.nih.gov/pubmed/13726518.

17. World Health Organization (WHO). Public Health Impact of Pesticides Used in Agriculture. Geneva: WHO, 1990.

18. Kettel B. Women, health and the environment. Soc Sci Med 1996; 42(10): 1367-1379. https://doi.org/10.1016/0277-9536(95)00285-5.

19. Murray DL. Cultivating crisis: the human cost of pesticides in Latin America. Austin: University of Texas Press, 1994.

20. Mbakaya CF, Ohayo-Mitoko GJ, Ngowi VA, Mbabazi R, Simwa JM, Maeda DN, et al. The status of pesticide usage in East Africa. Afr J Health Sci 1994; 1(1): 37-41. https://www.ncbi.nlm.nih.gov/pubmed/12150642.

\section{Authors:}

Ato Kwamena Tetteh - MPhil, Senior Biomedical Laboratory Scientist, Laboratory Department, Metropolitan Hospital, Cape Coast, Central Region, Ghana. http://orcid.org/0000-0002-7161-5868.

Gertrude Adu-Afari - MPhil Candidate, Laboratory Department, Metropolitan Hospital, Cape Coast, Central Region, Ghana. http://orcid.org/0000-0002-7824-9186.

Emmanuel Nana Yaw Effrim Botchway - MPhil Candidate, Laboratory Department, Cape Coast Teaching Hospital, Cape Coast, Central Region, Ghana. http://orcid.org/0000-0001-9074-6567.

Gifty Rhodalyn Tetteh - MA, Research Assistant, Department of Environmental Science, University of Cape Coast, Cape Coast, Central Region, Ghana. http://orcid.org/0000-0002-0537-7881.

Edward Agyarko - MPhil, Lecturer, Department of Community Medicine and Health, Anglican University College of Technology, Nkoranza, Brong Ahafo Region, Ghana. http://orcid.org/0000-0001-8562-4004 